\title{
User Experience Evaluation of Cross-Channel Consumption: Based on Grounded Theory and Neural Network
}

\author{
Hua Yang $(\mathbb{D}$, Huiying Wei $(\mathbb{D}$, Xiang He $\mathbb{D}$, Yue Yan $(\mathbb{D}$, and Xiaoju Liu \\ School of Management, Jilin University, China \\ Correspondence should be addressed to Hua Yang; yh2009@jlu.edu.cn
}

Received 3 August 2021; Revised 23 September 2021; Accepted 25 September 2021; Published 21 October 2021

Academic Editor: B. B. Gupta

Copyright (c) 2021 Hua Yang et al. This is an open access article distributed under the Creative Commons Attribution License, which permits unrestricted use, distribution, and reproduction in any medium, provided the original work is properly cited.

\begin{abstract}
With the rapid development of e-commerce technology, cross-channel consumption has become the mainstream mode of contemporary consumers. However, there are several problems of cross-channel consumption such as inconsistency of online and offline channel information and service, disfluency of channel switching which have brought adverse effects on user experience. The question arises here as to what factors influence user experience and how to build a scientific and effective evaluation index system. Different from previous studies based on sellers, this paper used grounded theory to analyze and summarize the evaluation index system of user experience under cross-channel consumption from the perspective of consumers. We summarized and refined four first level indexes which are "online platform attribute, offline entity attribute, channel switching attribute, and individual demand" and 13 second level indexes which are "platform operation, platform information, platform service, platform promotion, product quality, service quality, environment quality, channel consistency, channel switching cost, channel switching fluency, psychological expectation, personal interests and individual needs." Then, we used BP neural network to build the evaluation model and trained and simulated the performance of the sample. The results show that the evaluation model has a good generalization ability and can effectively evaluate user experience under cross-channel consumption. Finally, implications and limitations are also discussed. This study helps to enrich the theoretical research on user experience and consumer behavior. It also provides targeted basis for in-depth analysis of cross-channel consumption behavior, establishment of user experience evaluation index system, and improving user experience and multichannel management of physical stores.
\end{abstract}

\section{Introduction}

With the rapid development of e-commerce technology, it has become a common form that enterprises spread information, sell products, and provide services through e-commerce websites, mobile Apps, physical stores, and other channels $[1,2]$. When consumers are allowed to choose a variety of shopping channels, they may search for information in one channel, try and experience in another channel, which leads to the phenomenon of channel switching, namely, cross-channel consumption $[3,4]$. It refers to the process that consumers use a certain channel to obtain information and then experience and evaluate products in the other channel to complete the whole consumption [5]. Accordingly, consumers who study goods through one channel (such as the Internet) and purchase goods through another (such as physical stores) are called "research shopper" [6]. Research shows that about $43 \%$ of consumers are "research shoppers" [6]. They use one channel for search and another for purchase. Their fundamental reasons for research shopping are making decisions based on channel attribute, lack of channel lock-in, and crosschannel synergy. Cross-channel behavior has become a hot topic of consumer behavior research in multichannel environment [7-10].

According to the channel difference of information acquisition and order fulfillment, consumers' cross-channel behaviors can be divided into experience offline and purchase online, search online and experience offline, Buy/Reserve/Order Online and Pick up in store (BOPSROPS/OOPS), and various combination forms of online and offline behavior [11]. As consumers can freely shuttle between online and offline channel services, free riding between channels is very common [2]. 
If all the channels used by consumers in one purchase belong to retailers of the same brand, cross-channel retention behavior occurs. If multiple channels used by consumers belong to retailers of different brands, it is considered that customer loss occurs [10]. Therefore, it is very important for businesses to strengthen multichannel management, improve consumers' cross-channel retention behavior, and prevent customers from switching from one brand to another [8]. At present, businesses still have many problems in multichannel management [12]. Taking the mode of "search online and experience offline" of catering service industry as an example, in the whole process of online to offline consumption, consumers may often encounter problems such as frequent marketing and too many advertisements on online page; lack of dish pictures and poor display; inaccurate information of restaurants and dishes; delayed data; poor connection between online and offline channels and inconsistent information; low level of offline service; and poor quality of dishes. These problems greatly affect user experience and may lead to the loss of consumers $[13,14]$. Therefore, improving cross-channel consumption experience has become an important goal for businesses to carry out multichannel and even omni-channel management, which plays a very important role in maintaining brand loyalty, reducing the loss of consumers, and improving the competitiveness of enterprises [15].

Previous studies have either analyzed the impact of consumer behavior on channel decision-making based on mathematical models or focused on the antecedents of crosschannel behavior $[7,8,11]$. However, the evaluation and analysis of cross-channel consumer experience from the perspective of consumers are lacked [11]. How to evaluate user experience under cross-channel consumption? What is the impact of different channels and channel switching on user experience? The problems are very important issues for enterprises to carry out multichannel management and improve user stickiness and business performance. In order to solve the problem, taking the mode of "search online and experience offline" of catering service industry as an example, this study builds the evaluation index system of user experience under cross-channel consumption through the qualitative research method of grounded theory and verifies the established evaluation system through BP neural network, so as to provide reference and suggestions for mining and improving user experience of cross-channel consumption and improving enterprise competitiveness.

This paper is organized as follows. The first section has established our motivation and the research questions we are seeking to answer. In the second section, we review the relevant literatures on our phenomenon of interest-crosschannel consumption to construct the foundation for our subsequent theoretical arguments. The research design is then presented in the third section, including research method, sample and data analysis, and encoding process so that the reader may follow the process of theory building. In the fourth section, we judge the validity of the developed theory based on BP neural network. The fifth section of the paper presents analysis and discussion of the results. The sixth section presents the key arguments inductively derived from the study, as well as their theoretical implications before a discussion of the limitations and practical contributions of our study in the concluding section of the paper.

\section{Literature Review}

It is an important issue for scholars that how consumer behavior as a key variable affects business decision-making. The existing research of cross-channel consumption can be divided into two categories. (1) the impact of consumer cross-channel behavior on product pricing, ordering, service provision, and other decisions, and how to optimize and improve the supply chain performance through mathematical modeling, game theory, etc. For example, Mittelstaedt [16] found that consumers' free riding behavior greatly inhibited retailers' enthusiasm to provide information services. Van Baal and Dach [17] found that in the dual channel supply chain composed of physical stores and online stores, the proportion of consumers who take "free riding" behavior is as high as $20 \%$. Consumers' free riding behavior weakens the enthusiasm of physical stores' promotion efforts and inhibits the growth of manufacturers' market demand. Therefore, manufacturers are actively building online direct sales channels on the one hand. On the other hand, they have to face the competition and conflict between online stores and physical stores [17]. The research of Huang et al. [18] show that the change of consumers' preference and demand for online store sales will significantly affect the price strategy of physical stores and the production strategy of manufacturers. Dan et al. [19] studied the impact of consumer cross-channel behavior and channel service competition on channel members' decision-making and designed corresponding contracts to adjust service level and improve channel members' performance. The research of Pu and Gong [20] shows that the sale effort level of traditional retailers and the profit of the supply chain decrease with the number of free riding increase. The sharing mechanism of promotion cost can realize the Pareto improvement of the profits of both sides and improve the efficiency of the supply chain [20]. Zhou et al. [21] studied the dual channel pricing and service problems under the condition of sharing costs between online service and offline service. The research found that the impact of free riding behavior on manufacturer's pricing depends on the price sensitivity and service cost between channels. When the price sensitivity between channels is relatively large, free riding will have a negative impact on manufacturer's online channel pricing [21]. Yang et al. [22] built a price decision model of dual channel supply chain considering cross-channel return strategy. The results show that the optimal price of the retailer channel is directly proportional to the customers' preference for the channel and the return rate. When customers have a high preference for a certain channel, the profit under decentralized decision-making is higher than that under centralized decision-making. And with the increase of the return rate of the channel, the profit gap will further expand. Therefore, retailers should implement the channel strategy of decentralized decision-making and encourage the competition between online and offline channels so as to obtain greater profits [22]. Wang et al. [23] adopted social network 
analysis (SNA) to build social networks reflecting consumers' overall evaluation in the $\mathrm{O} 2 \mathrm{O}$ model and extract eleven indexes with Crawlzilla and $\mathrm{R}$ techniques which show that perceived product quality, online product price, promotion intensity, business reputation, and product brand reflect the significant associations between the indexes [23]. Using European customer satisfaction index and service performance-aware service quality measurement method as a logical framework, Liang et al. [24] adopt content analysis to construct the evaluation system of customer satisfaction. They develop a combination way to calculate the index weights and fuzzy comprehensive evaluation method to calculate the customer satisfaction level [24].

(2) Based on customer management theory, the crosschannel behavior of consumers is investigated and analyzed through empirical method and the antecedents, and their effects are explained. For example, Kollmann et al. [25] studied the formation mechanism of synergy and competition effect between channels from the perspective of consumers' motivation of cross-channel behavior [25]. Cui and Zhu [26] constructed the influencing factor model of consumption experience under $\mathrm{O} 2 \mathrm{O}$ mode (online to offline). It pointed out that the degree of personalization of consumption experience has the greatest influence on consumption experience, followed by interactivity, culture, and process [26]. Through empirical analysis, Kong et al. [27] found that the integration capabilities of online and offline channel based on information technology have a positive impact on customer experience, which include prepurchase integration capability, in purchase integration capability, and postpurchase integration capability. Chia-Chen et al. [28] discussed whether consumer experience and behavior can be transferred between physical and virtual channels. Hu et al. [29] explored the dual influence and dynamic evolution mechanism of habit in channel expansion based on trust transfer and status quo preference theory, as well as the influence of different promotion strategies on channel expansion behavior. The results show that the original channel habits influence consumers' use of new channels through positive promotion mechanism and negative pull mechanism. In different stages of channel expansion, the influence mechanism of habits will change [29]. Based on the serviceoriented perspective, Shen et al. [30] proposed that omnichannel retail enterprises should enhance the value cocreation behavior from the aspects of service products, service interaction, and experience environment so as to enhance the user experience. Maggioni et al. [31] analyzed crosschannel consumption behavior based on multiattribute utility theory. It pointed out that cross-channel behavior often originates from factors beyond the control of consumers such as planning, compulsion, or opportunism, while these factors are often controllable within the control of retailers [31]. Through the push-pull-mooring approach, Haridasan et al. [32] confirmed that in the cross-channel context, the push (the degree of external information search) and pull (alternative attraction) factors have a positive impact on the channel switching intentions. Yang et al. [33] build a research model integrating perceived value theory and the technology acceptance model to examine the influence of the features of $\mathrm{O} 2 \mathrm{O}$ commerce on consumer use intention. Two crucial features of physical experience and integration of online and offline information are shown to exert significant impacts on consumer use intention via the classic core constructs of perceived benefit, perceived usefulness, and perceived value [33]. Kim et al.'s [34] research confirms that qualified information and services of $\mathrm{O} 2 \mathrm{O}$ mobile shopping application (MSA) positively affect both perceived privacy protection and customer satisfaction, which finally lead to customer loyalty through the lens of the information systems success model. Utilizing the innovation resistance theory (IRT) and a convergent mixed-method study, Talwar et al. [35] examine the barriers that users of food delivery apps (FDA) face. They identified three key barriers of economic, efficiency, and experience. It also supports the negative association of barriers with trust and paradoxical recommendation and verified the mediating effect of trust and the moderating effect of advertising overload on the identified association [35].

The two types of studies have drawn useful conclusions for multichannel management. For example, the research on mathematical model focuses on the impact of consumer behavior on channel decision-making. But it mainly focuses on one aspect of the problem and does not explore a variety of coordination factors among channels. Empirical literature focuses on the antecedent variable analysis of cross-channel behavior. However, the research on the combination of customer management with multichannel operation and performance improvement is seldom. And there is a lack of evaluation and analysis of cross-channel consumer experience [11]. In fact, in the process of cross-channel consumption, consumers often encounter various problems such inconsistency of channel information and service, disfluency of channel switching in multiple links, and contacts from online use to offline experience, which may have a negative impact on user experience and lead to the decrease of user stickiness. So how to evaluate user experience of consumers in cross-channel consumption? What are the evaluation dimensions? How to improve the user experience of crosschannel consumption? In view of the above problems, this paper intends to conduct in-depth interviews with crosschannel consumer users and build the evaluation index system of user experience based on the grounded theory method. Then, BP neural network will be used to verify the proposed evaluation system.

\section{Research Design}

3.1. Methodology. In this study, we believe that the establishment of the user experience evaluation system under crosschannel consumption should comprehensively consider the complexity of user experience. It should not only be limited to just combing the relevant literature but also should conduct more in-depth investigation and analysis. Therefore, this paper chooses grounded theory as the preliminary qualitative research method and constructs the evaluation system based on the actual interview materials. Grounded theory is a qualitative research method proposed by Barney Glaser and Anselm Strauss of Columbia University in the book 
TABle 1: Distribution of the interview sample.

\begin{tabular}{|c|c|c|c|c|c|c|c|}
\hline Name & Category & Frequency & Percentage & Name & Category & Frequency & Percentage \\
\hline \multirow{2}{*}{ Gender } & Male & 16 & $44.44 \%$ & \multirow{4}{*}{ Interview form } & Offline & 30 & $83.33 \%$ \\
\hline & Female & 20 & $55.56 \%$ & & Online & 6 & $16.67 \%$ \\
\hline \multirow{2}{*}{ Age } & $19-26$ & 25 & $69.44 \%$ & & \multirow{2}{*}{ Below 1000} & \multirow{2}{*}{5} & \multirow{2}{*}{$13.89 \%$} \\
\hline & $27-34$ & 11 & $30.56 \%$ & & & & \\
\hline \multirow{3}{*}{ Academic degree } & Below bachelor's degree & 5 & $13.89 \%$ & \multirow{3}{*}{ Monthly living expense (yuan) } & $1000-1500$ & 15 & $41.67 \%$ \\
\hline & Bachelor's degree & 22 & $61.11 \%$ & & $1500-2000$ & 12 & $33.33 \%$ \\
\hline & Above bachelor's degree & 9 & $25 \%$ & & Above 2000 & 4 & $11.11 \%$ \\
\hline
\end{tabular}

(The discovery of grounded theory: strategies for qualitative research). This method is aimed at analyzing the original data collected systematically and drawing conclusions for a certain social phenomenon. In order to ensure the rigor and integrity of the research, we draw lessons from the grounded theory research paradigm proposed by Pandit which is widely recognized by academic circles [36]. First, the research objects are defined and the samples are selected according to the research question. Second, through semistructured interviews with the interviewees, the original data were obtained and imported into data analysis tools. Third, the core category and the relationship between the categories are extracted through open coding, principal axis coding, selective coding, and theoretical saturation test. Finally, a theory rooted in real data is formed.

3.2. Sample and Data Source. We take catering service industry as an example for data collection which is one of the most widely applied industries in cross-channel consumption. Nowadays, many consumers may search information of dishes and service before going to the restaurant. They want to find the restaurant that best meets their needs. Then, they will go to find it and begin their dining experience. This is the mode "search online and experience offline" of crosschannel consumption. We take consumers of this mode as the survey object. In order to ensure the reliability of the data, we design the interview outline after literature analysis and consulting researchers with rich experience before the formal interview. According to the 43rd "Statistical Report on the development of Internet in China" and "Research Report on the Consumption Search Trend of Hotel and Catering Industry," youth group (19-34 years old) is not only the main user group of Internet but also the main user group of cross-channel catering consumption. Some studies have shown that young users tend to have higher information literacy than other groups [37]. So the interviewees are identified as college students and young office workers. Rather than random sampling, we select the respondents by indirect referrals of the researchers' personal network relationship in which we have a weak connection relationship with the interviewees so as to ensure the cooperation degree of the interviewees and the reliability of the data as far as possible.

In order to ensure the validity of the data, the triangle test proposed by Locke [38] is used, which includes the design method of interview outline mentioned above, repeated confirmation of ambiguous questions, or unclear questions expressed by the interviewees, follow-up to the question to prevent the respondent from thinking in-depth or guessing the answer to the question out of thin air so as to ensure that the answers are consistent with the reality as much as possible. Based on the validity control method of Strauss et al. [39], the rigor of rooting process is comprehensively guaranteed through mutual verification, memorandum writing, and expert analysis. Different coding results are compared, explained, and discussed. For the results that cannot be agreed, the experts in the field will be consulted and finally reach an agreement so as to ensure the validity of coding as far as possible.

From the beginning of July 2020 to the beginning of August 2020, we selected 6 interviewees for preinterview and found the deficiencies and problems of the outline. Then, we revise and improve the outline to form a formal interview outline which include basic information of the interviewees, cross-channel consumption experience, and factors influencing user experience under cross-channel consumption. Formal interviews were conducted from early September 2020 to the end of November 2020. In the preliminary stage of model construction, a total of 30 in-depth interviews were conducted and in the test stage of model theory saturation, and a total of 6 in-depth interviews were conducted. The basic information of the interviewees was as Table 1.

Finally, a total of 36 formal interview records were collected including the interview audio recorded with the consent of the interviewees and the documents directly edited during the interview. Then the voice records were transcribed and sorted out to form a formal interview text of more than 120000 words. According to the order of interviews, they were named from P1 to P36. A standardized processing of all the materials were done including simple text sorting, excluding some irrelevant, vague, and simple contents without substantive meaning so that the effective interview content can be extracted. On this basis, this study randomly selected 28 interview texts for data analysis and constructed the theoretical model through three-tier grounded theory coding. At the same time, 8 interview texts are reserved to test the saturation of the obtained theory. Then, the text data was imported into NVIVO 11 software which is commonly used in qualitative research to prepare for further data analysis.

3.3. Encoding Process. Data analysis is carried out according to the three-level coding requirements of grounded theory in 
TABLE 2: Excerpts of interview text and some examples of conceptualization.

\begin{tabular}{|c|c|}
\hline Partial source data & Conceptualization \\
\hline $\begin{array}{l}\text {...(for APP) the location information is clearly marked. We can easily find the restaurant. If we can't find it, the } \\
\text { functions of search, navigation, and others can be used which are particularly convenient... }\end{array}$ & Convenience \\
\hline $\begin{array}{l}\text {... when my friends and I search the same content on the platform, the page content we see is generally } \\
\text { different, which may be due to the different restaurants we have historically inquired and visited... }\end{array}$ & Individualization \\
\hline $\begin{array}{l}\text {...the restaurants on the app platform provide very detailed information for the dishes and environment, which } \\
\text { is very helpful for me to know about the restaurants... }\end{array}$ & Comprehensiveness \\
\hline $\begin{array}{l}\text {...I think the promotion activities on the platform are very powerful, such as giving coupons to new users, full } \\
\text { reduction, discount, package offers, and other activities which can save us a lot of money. }\end{array}$ & Cost-effective \\
\hline $\begin{array}{l}\text {...this dish is the specialty of the restaurant. I like it. Other restaurants do not have it or the taste is not as good } \\
\text { as this one. }\end{array}$ & Product uniqueness \\
\hline ...if the service attitude of the restaurant is friendly, I will be happy and have a good meal... & Emotional experience \\
\hline $\begin{array}{l}\text {...for example, I like the cartoon of pirate king very much. So if I see a restaurant with this kind of theme, I will } \\
\text { definitely go to have a look... }\end{array}$ & Style attractiveness \\
\hline $\begin{array}{l}\text {...the pictures of dishes online given by the restaurant is not consistent with the actual situation. The plates on } \\
\text { the pictures are very delicate. But when I go to eat in the restaurant, they do not look so delicate.... }\end{array}$ & $\begin{array}{l}\text { Product information } \\
\text { consistency }\end{array}$ \\
\hline $\begin{array}{l}\text {...it's similar to the comments online. Once we went to a barbecue, the waiters helped us collect garbage and } \\
\text { empty dishes. The comments online also mentioned these... }\end{array}$ & $\begin{array}{l}\text { Service content } \\
\text { consistency }\end{array}$ \\
\hline $\begin{array}{l}\text {...according to the address given by the online platform, it is quite easy to find the store. The address is usually } \\
\text { directly linked to the navigation, I will choose a familiar navigation such as Gao De navigation and follow the } \\
\text { planned route. It is usually easy to find it.... }\end{array}$ & Switching difficulty \\
\hline $\begin{array}{l}\text {......the dishes I ordered can meet my needs of taste, safety, and hygiene. So it can achieve my psychological } \\
\text { expectations...... }\end{array}$ & Product expectation \\
\hline $\begin{array}{l}\text {...I think it is very efficient to search restaurants online. I can compare products, prices, locations, and so on, } \\
\text { and then go to the restaurants for consumption. It allows me to find my favorite restaurants quickly and saves a } \\
\text { lot of time compared with directly looking for restaurants offline... }\end{array}$ & Efficiency \\
\hline $\begin{array}{l}\ldots \text { searching and comparing restaurants online can make me know more about dishes and environment. So I } \\
\text { can choose the restaurant that I like and then go for dining, which can further improve my satisfaction...... }\end{array}$ & Knowledge \\
\hline
\end{tabular}

which different expressions of the same meaning in the same interview material are regarded as different reference points. The same expression of the same meaning is only regarded as one reference point. In addition, a reference point may be summed up in multiple open codes at the same time.

3.3.1. Open Coding. Open coding is to refine and integrate the original statement to form a new concept. It is a process of conceptualization and categorization of collected data to obtain concepts and categories closest to the nature of the data. First, the in-depth interview contents of the previous 30 interviewees were sorted out and analyzed. Through open coding, 361 label concepts and 41 initial concepts were obtained. Some of the original statements and their conceptualization are shown in Table 2. Then, the initial concept was categorized, and 13 categories were got, as shown in Table 3.

3.3.2. Spindle Coding. Spindle coding is to generate clear and controllable main categories through making attribute analysis and cluster analysis of open coding results. By refining the categories and specifying the dimensions of each subcategory, the category nodes with larger concepts are formed, and the relationship between nodes is determined. Finally, 4 main categories are formed through the analysis, induction, and abstraction of the 13 emerging categories which are online platform attribute, offline entity attribute, channel switching attribute, and individual demand. On this base, the user experience evaluation system under cross-channel consumption is constructed. Each subcategory and its main category are shown in Table 4.

3.4. Theoretical Saturation Test. Using the reserved 8 interview texts for theoretical saturation test, no new important concepts or other categories that can explain the research problems are found. Therefore, it can be considered that the theoretical model has reached saturation.

\section{Verification of the Evaluation Index System}

4.1. The Principle of BP Neural Network. BP (back propagation) neural network is a nonlinear system which simulates the information processing method of the human brain. It is a multilayer feedforward network trained by error back propagation algorithm. It is one of the most widely used neural network models at present. BP network can learn and store a large number of input-output mode mapping relationships without revealing the mathematical equations describing this mapping relationship in advance. Its learning rule is to use the steepest descent method and continuously adjust the weight and threshold of the network through back propagation to minimize the sum of squares of the network error. In order to verify the index system of the user experience evaluation of cross-channel consumption proposed above, we use BP neural network to test the actual usability 
TABLE 3: The initial concepts and categories constructed by open coding.

\begin{tabular}{lc}
\hline Initial concepts & Categories \\
\hline A1 conciseness, A2 convenience, A3 reliability & B1 platform operation \\
A4 professionalism, A5 responsiveness, A6 emotional care, A7 personalization & B2 platform service \\
A8 accuracy, A9 comprehensiveness, A10 diversity, A11 timeliness & B3 platform information \\
A12 abundance, A13 discounts & B4 platform promotion \\
A14 sensory, A15 taste, A16 safety and reliability, A17 uniqueness & B5 product quality \\
A18 service innovation, A19 service responsiveness, A20 service friendliness & B6 service quality \\
A21 hygiene, A22 style attractiveness, A23 layout rationality & B7 environment quality \\
A24 transportation convenience & B8 channel consistency \\
A25 channel information consistency, A26 channel service consistency & B9 channel switching cost \\
A27 time cost, A28 economic expense & B10 channel switching coherence \\
A29 switching difficulty, A30 correlation degree, A31 fluency degree & B11 individual psychological expectation \\
A32 product expectation, A33 service expectation, A34 environment expectation & B12 personal interest \\
A35 price expectation & B13 personalized demand \\
A36 entertainment, A37 fun, A38 knowledge & \\
A39 convenience, A40 efficiency, A41 flexibility &
\end{tabular}

TABLE 4: Subcategories and main categories.

\begin{tabular}{|c|c|c|c|}
\hline $\begin{array}{l}\text { The main } \\
\text { category }\end{array}$ & Subcategory & Subcategory meaning & Material source \\
\hline \multirow{4}{*}{$\begin{array}{l}\text { C1 online } \\
\text { platform } \\
\text { attribute }\end{array}$} & $\begin{array}{l}\text { B1 platform } \\
\text { operation }\end{array}$ & $\begin{array}{c}\text { User experience when searching, browsing, selecting, etc. on the online } \\
\text { platform. }\end{array}$ & $\begin{array}{l}{[\mathrm{P} 01, \mathrm{P} 03, \mathrm{P} 05-\mathrm{P} 14} \\
\mathrm{P} 16, \mathrm{P} 18-\mathrm{P} 24, \mathrm{P} 26]\end{array}$ \\
\hline & B2 platform service & $\begin{array}{l}\text { User experience in professionalism, responsiveness, emotional care, and } \\
\text { personalization of services provided by the platform. }\end{array}$ & $\begin{array}{l}{[\mathrm{P} 01, \mathrm{P} 03-\mathrm{P} 07, \mathrm{P} 10-} \\
\mathrm{P} 15, \mathrm{P} 18-\mathrm{P} 23, \mathrm{P} 25-26]\end{array}$ \\
\hline & $\begin{array}{l}\text { B3 platform } \\
\text { information }\end{array}$ & $\begin{array}{l}\text { User experience on the accuracy, comprehensiveness, and timeliness of } \\
\text { the information displayed on the platform. }\end{array}$ & $\begin{array}{l}{[\mathrm{P} 01-\mathrm{P} 05, \mathrm{P} 07-\mathrm{P} 08} \\
\mathrm{P} 10-\mathrm{P} 18, \mathrm{P} 20-\mathrm{P} 25]\end{array}$ \\
\hline & $\begin{array}{l}\text { B4 platform } \\
\text { promotion }\end{array}$ & $\begin{array}{l}\text { User experience of the abundance and discounts of promotional } \\
\text { activities provided by the platform. }\end{array}$ & $\begin{array}{l}{[\mathrm{P} 04, \mathrm{P} 06-\mathrm{P} 07, \mathrm{P} 09-} \\
\text { P14, P16-17, P19, P23] }\end{array}$ \\
\hline \multirow{3}{*}{$\begin{array}{l}\mathrm{C} 2 \text { offline entity } \\
\text { attribute }\end{array}$} & B5 product quality & $\begin{array}{l}\text { User experience of sensory, taste, safety, and reliability, uniqueness of the } \\
\text { product provided by the physical store. }\end{array}$ & $\begin{array}{l}{[\mathrm{P} 01-\mathrm{P} 03, \mathrm{P} 05-\mathrm{P} 15} \\
\quad \mathrm{P} 17-\mathrm{P} 24, \mathrm{P} 26]\end{array}$ \\
\hline & B6 service quality & $\begin{array}{c}\text { User experience of innovation, responsiveness, friendliness of the service } \\
\text { provided by the physical store. }\end{array}$ & $\begin{array}{l}{[\mathrm{P} 01-\mathrm{P} 05, \mathrm{P} 08-\mathrm{P} 13} \\
\mathrm{P} 15, \mathrm{P} 18-\mathrm{P} 24, \mathrm{P} 26]\end{array}$ \\
\hline & $\begin{array}{l}\text { B7 environment } \\
\text { quality }\end{array}$ & $\begin{array}{l}\text { User experience of the hygiene, style attractiveness, layout rationality, } \\
\text { and transportation convenience of environment of the physical store. }\end{array}$ & $\begin{array}{l}{[\mathrm{P} 03, \mathrm{P} 05-\mathrm{P} 14, \mathrm{P} 16} \\
\mathrm{P} 18-\mathrm{P} 20, \mathrm{P} 22, \mathrm{P} 24]\end{array}$ \\
\hline \multirow{3}{*}{$\begin{array}{l}\text { C3 channel } \\
\text { switching } \\
\text { attribute }\end{array}$} & $\begin{array}{l}\text { B8 channel } \\
\text { consistency }\end{array}$ & $\begin{array}{l}\text { User experience on the similarity degree of product information and } \\
\text { services in different channels }\end{array}$ & $\begin{array}{l}{[\mathrm{P} 02, \mathrm{P} 03, \mathrm{P} 05-\mathrm{P} 14} \\
\mathrm{P} 16, \mathrm{P} 18-\mathrm{P} 22, \mathrm{P} 24]\end{array}$ \\
\hline & $\begin{array}{l}\text { B9 channel switching } \\
\text { cost }\end{array}$ & $\begin{array}{l}\text { User experience on the time and cost of channel switching. } \\
\text { User experience on the difficulty and fluency of switching between }\end{array}$ & $\begin{array}{l}{[\mathrm{P} 03-\mathrm{P} 05, \mathrm{P} 08-\mathrm{P} 16} \\
\mathrm{P} 18, \mathrm{P} 20, \mathrm{P} 23-26]\end{array}$ \\
\hline & $\begin{array}{l}\text { B10 channel } \\
\text { switching coherence }\end{array}$ & $\begin{array}{l}\text { User experience on the dimcuity and riluency or switching between } \\
\text { different channels. }\end{array}$ & $\begin{array}{l}{[\mathrm{P} 01-\mathrm{P} 07, \mathrm{P} 09-\mathrm{P} 13} \\
\mathrm{P} 15-\mathrm{P} 23, \mathrm{P} 25]\end{array}$ \\
\hline \multirow{3}{*}{$\begin{array}{l}\text { C4 individual } \\
\text { demand }\end{array}$} & $\begin{array}{l}\text { B11 individual } \\
\text { psychological } \\
\text { expectation }\end{array}$ & $\begin{array}{l}\text { User experience on the achievement of psychological expectation in the } \\
\text { process of cross-channel consumption. }\end{array}$ & $\begin{array}{l}{[\mathrm{P} 02-\mathrm{P} 04, \mathrm{P} 06-\mathrm{P} 15} \\
\mathrm{P} 17, \mathrm{P} 18-\mathrm{P} 23, \mathrm{P} 25]\end{array}$ \\
\hline & B12 personal interest & User experience on entertainment, interest and knowledge gained in the & $\begin{array}{l}{[\mathrm{P} 03-04, \mathrm{P} 06, \mathrm{P} 09-16} \\
\text { P19-P24] }\end{array}$ \\
\hline & $\begin{array}{l}\text { B13 personalized } \\
\text { demand }\end{array}$ & $\begin{array}{l}\text { The satisfaction degree of users in convenience, flexibility, and other } \\
\text { personalized needs in the process of cross-channel consumption. }\end{array}$ & $\begin{array}{l}\text { [P01-P06, P08-P14, } \\
\text { P16, P18-P23, P25- } \\
\text { P26] }\end{array}$ \\
\hline
\end{tabular}

of the evaluation system so as to enhance the practical value of the research.

The typical BP network structure is a model composed of three neuron layers which are the input layer, the intermediate hidden layer, and the output layer, as shown in Figure 1. The input layer transmits the stimulus to the hidden layer. The hidden layer transmits the stimulus to the output layer through the weights and transfer rules (activation function) 


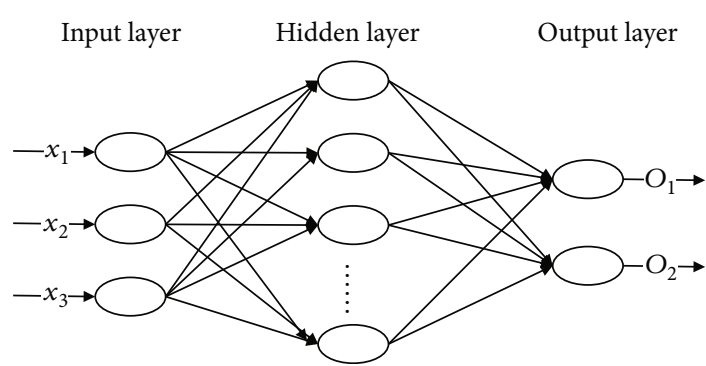

Figure 1: Typical structure of BP neural network.

between neurons. And the output layer collates the stimulus processed by the hidden layer to produce the result. Then, it will be compared with the actual result to get the error. And the link weight in the neural network will be retrograde and corrected so the learning process is completed.

4.2. Data Collection through Questionnaire. As mentioned above, college students and young office workers have a higher frequency of cross-channel consumption in the catering industry. So taking them as the object of the survey, combining on-site distribution and online survey, a total of 192 questionnaires were distributed in which 164 valid questionnaires were recovered. The effective recovery rate was $85.42 \%$. The descriptive statistical results of the sample are shown in Table 5. It can be seen that the distribution of gender and educational background of the respondents is relatively balanced, and the frequency of cross-channel consumption is relatively high.

In the main part of the questionnaire, the evaluation index system constructed above is designed by Likert 7 level scale with 7 levels from "very dissatisfied" to "very satisfied," corresponding to 1-7 points, respectively. The experience of cross-channel consumption is rated according to the satisfaction degree of respondents which includes 1-5 grades from low to high, corresponding to five evaluations from "very dissatisfied, relatively dissatisfied, generally satisfied, relatively satisfied and very satisfied." Part of the data obtained from the survey is shown in Table 6.

\subsection{Learning Process of BP Neural Network}

4.3.1. Processing of Input Value and Output Value. For the collected data, the scores of 13 secondary indexes were taken as the input values, and user ratings were taken as output values. 82 valid questionnaires were randomly selected from 164 valid questionnaires as training sets, and the remaining 82 questionnaires were used as test sets. In order to ensure the convergence of the network, the training data was read by MATLAB R2016 a, and the mapminmax() function was used to normalize the sample data.

4.3.2. BP Neural Network Training. The transfer function of neurons in the middle layer of BP neural network constructed in this study was logarithmic S-shaped transfer function $\log \operatorname{sig}()$. And the training function was set as traingdx () . The target error of neural network training was set to 0.001 . The maximum number of iterations was set to 1000 , and the learning rate was set at 0.001 . After the net- work learning had been completed, the test data was read, and the generated network model was used to simulate the output of the input samples using the function sim (). Finally, the accuracy of statistical identification was output.

In this study, there were 13 neurons in the input layer and 1 neuron in the output layer. When determining the number of neurons in the intermediate hidden layer, we referred to the empirical formula: $h=\sqrt{n+m}+\propto$, where $h$ is the number of neurons in the intermediate hidden layer. $n$ is the number of neurons in the input layer, and $m$ is the number of neurons in the output layer. $\propto$ is a constant between 1 and 10. Through the comparison of experiments and considering the time cost of machine learning, the number of iterations, and the error size, the number of hidden layer nodes was determined to be 6 .

4.4. The Result of the Output. The output results are shown in Figure 2. It can be seen that after initialization of BP neural network and 151 times of iteration, the error of the model meets the requirements of the set standard. The correct rate of the recognition of user experience rating can reach $97 \%$ which is close to $100 \%$ and relatively stable.

The linear regression relationship between the value of actual output and the expected output is shown in Figure 3. The value of actual output is obtained by simulating the input sample through the trained BP neural network with the simulation function. The expected value is the user rating obtained through questionnaire. The regression coefficient is $R=0.97297$ which is very close to 1 . It means that the simulation value is in good agreement with the actual observation value and the error is small. The weights and thresholds of the trained BP neural network are appropriate. The network model has strong simulation ability. Therefore, the BP neural network can effectively evaluate the user experience of cross-channel consumption.

\section{Analysis and Discussion}

In this paper, taking the mode of "search online and experience offline" of catering service industry as an example, the evaluation index system of user experience under crosschannel consumption is constructed through semistructured in-depth interviews and grounded theory qualitative method. We put forward 4 first level indexes which are online platform attribute, offline entity attribute, channel switching attribute, and individual demand and 13 secondary indexes. Then, a survey on user experience of crosschannel consumption was done, and the actual usability of the evaluation index system is tested by BP neural network.

In terms of online platform attributes, 4 secondary indexes are put forward which are platform operation, platform service, platform information, and platform promotion. In the process of cross-channel consumption, consumers generally search for product information online through e-commerce platforms (including computer and mobile terminals) to form online perception preference and evaluation of restaurants and products. The search experience of the platform has a direct impact on further consuming behavior. The conciseness, convenience, and reliability of the platform operation 
TABLe 5: Descriptive statistical analysis.

\begin{tabular}{|c|c|c|c|}
\hline Statistics & Frequency & \multicolumn{2}{|c|}{ Percentage (\%) } \\
\hline \multirow{2}{*}{ Gender } & Male & 85 & 51.83 \\
\hline & Female & 79 & 48.17 \\
\hline \multirow{3}{*}{ Education } & Associate degree and below & 61 & 37.20 \\
\hline & Bachelor degree & 54 & 32.93 \\
\hline & Master degree or above & 49 & 29.87 \\
\hline \multirow{3}{*}{ Cross-channel consumption frequency } & Often (more than or equal to 4 times a month) & 94 & 57.32 \\
\hline & Occasionally (2 or 3 times a month) & 53 & 32.32 \\
\hline & Rarely (one time a month) & 17 & 10.36 \\
\hline
\end{tabular}

TABle 6: Survey data (part).

\begin{tabular}{cccccccccccccc}
\hline B1 & B2 & B3 & B4 & B5 & B6 & B7 & B8 & B9 & B10 & B11 & B12 & B13 & B14 \\
\hline 6 & 5 & 6 & 6 & 7 & 6 & 6 & 5 & 5 & 5 & 6 & 6 & 6 & 5 \\
4 & 5 & 4 & 5 & 5 & 4 & 4 & 4 & 5 & 5 & 4 & 4 & 5 & 4 \\
6 & 6 & 7 & 6 & 6 & 7 & 6 & 7 & 7 & 6 & 7 & 6 & 7 & 5 \\
4 & 4 & 3 & 4 & 4 & 3 & 5 & 4 & 4 & 4 & 4 & 4 & 3 & 3 \\
5 & 6 & 5 & 6 & 6 & 5 & 6 & 6 & 7 & 6 & 6 & 6 & 5 & 5 \\
4 & 3 & 4 & 5 & 4 & 4 & 4 & 4 & 5 & 4 & 5 & 4 & 4 & 4 \\
4 & 6 & 4 & 5 & 4 & 4 & 5 & 5 & 5 & 4 & 5 & 4 & 4 & 3 \\
7 & 6 & 7 & 6 & 7 & 6 & 6 & 7 & 6 & 7 & 6 & 5 & 6 & 5 \\
5 & 5 & 4 & 5 & 4 & 4 & 5 & 4 & 5 & 5 & 4 & 6 & 5 & 3 \\
2 & 3 & 2 & 3 & 2 & 3 & 3 & 2 & 3 & 3 & 3 & 2 & 3 & 2 \\
\hline
\end{tabular}

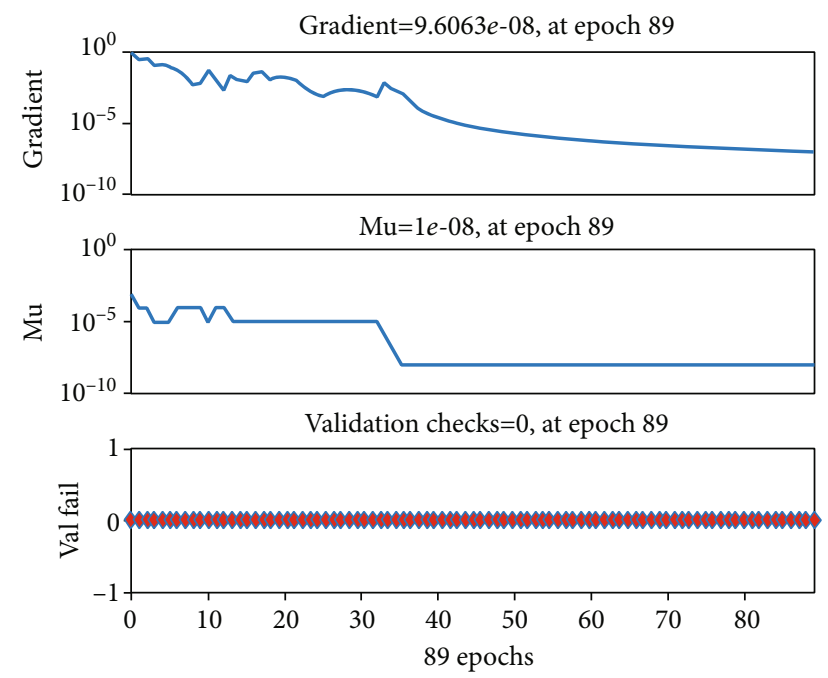

FIGURE 2: Training situation.

will help consumers to find the information they want. The more accurate, comprehensive, and timely of the platform information, the better the user's value experience of products. The more professional, responsive, emotional care, and personalized of the platform service, the better the user's value experience of the service. The richness and intensity of the platform's promotion are the motivation for users to consume, which may prompt users' further offline experience and purchase. The influencing factors such as platform information and platform promotion found in this study further verify the previous studies of Wang et al. [23] and Kim et al. [34]. Therefore, the first level index of "online platform attribute" reflects the value of cognition of user experience in the process of using platform online based on platform operations, centered on platform information and services, and externally driven by platform promotion.

In terms of offline entity attributes, 3 secondary indexes are put forward which are product quality, service quality, and environmental quality. In the process of cross-channel consumption, consumers carry out offline experience to form perceived preference and comprehensive evaluation of physical stores and its environment. Product is the main object of user consumption. Its attributes including sensory, taste, uniqueness, safety, and reliability are the important influencing factors of user's perception of product quality. The innovation, responsiveness, and friendliness of service will affect user's emotional experience during consuming. The hygiene, style attractiveness, layout rationality, and transportation convenience of the internal and external of the physical store will influence the use's environmental experience, which are consistent with the research of Yang et al. [33] and Cui [40] to a great extent. These three aspects together form the consumer experience of offline store consumption. So the first level index of "offline entity attribute" reflects the cognition value of user experience in physical store taking product quality, service quality, and environment quality as the basic elements.

In terms of channel switching attribute, 3 secondary indexes are put forward which are channel consistency, channel switching cost, and channel switching coherence. Under cross-channel consumption, users often hope that information of products and services between different channels can maintain high consistency in the process of switching of different channels so as to reduce the cost of comparison. On the other hand, the time cost and economic cost are important factors for channel switching. The lower the cost, the stronger the power of user to switching channel. In addition, seamless connections between different channels can promote the smooth switching between channels, which also further verified the conclusion of PicotCoupey et al. [12] and Gao et al. [41]. The correlation between channels, the switching difficulty, and the fluency of the switching process will influence user experience. Therefore, the first level index of "channel switching 


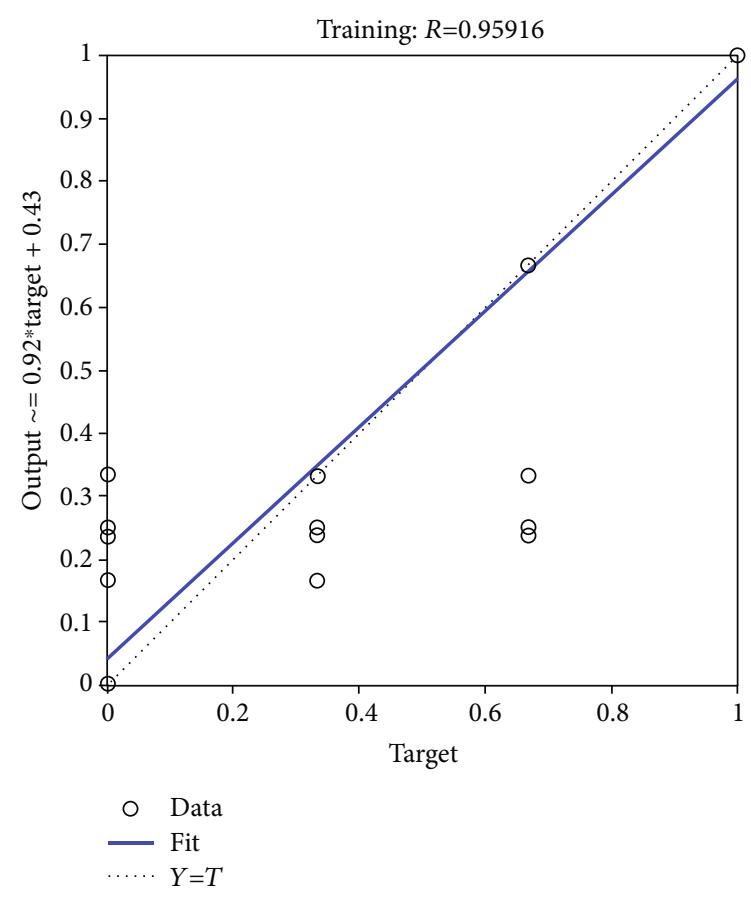

FIgURe 3: Regression curve.

attribute" reflects the value cognition of user experience of different channel switching which is based on channel consistency, driven by channel switching cost, and depended on channel switching coherence.

In terms of individual demand, 3 secondary indexes are put forward which are individual psychological expectation, personal interest, and personalized demand. First of all, we think that when users consume, they have psychological expectations on whether consumption behaviors can meet their needs and hope to get positive returns. Psychological expectation reflects the psychological satisfaction of users in the process of consumption, which is one of the internal driving forces for users to actively participate in consuming. Second, personalized needs and personal interests reflect different aspects of user needs. Different users have different purposes for cross-channel consumption. Some consumers hope to save time, facilitate life, and save expenses through cross-channel consumption, while some users are for entertainment, curiosity, knowledge growth, and vision expansion. They are usually interest-oriented to participate in cross-channel consumption. This is consistent with the research of Zhang and Wang [42]. In general, the first level index of "individual demand" reflects the personal psychological cognition of user experience in the process of crosschannel consumption. It is an important internal motive force for users to consume across channels.

\section{Conclusion}

6.1. Conclusions. Taking catering service industry as an example, this study makes a systematic exploration and holographic analysis on the influencing factors of crosschannel consumer user experience. We construct an evaluation index system of user experience of cross-channel con- sumption based on the grounded theory, in which 4 first level indexes of "online platform attribute, offline entity attribute, channel switching attribute, and individual demand" and 13 secondary indexes of "platform operation, platform information, platform service, platform promotion, product quality, service quality, environment quality, channel consistency, channel switching cost, channel switching fluency, psychological expectation, personal interests and individual needs " are put forward.

At the application level, the users of cross-channel consumption are investigated and analyzed. The BP neural network is used to evaluate and verify the evaluation index system. Data analysis shows that the evaluation index system is operable in practice and can provide reference for research of cross-channel consumption and related platforms and enterprises.

\subsection{Theoretical and Managerial Implications}

6.2.1. Theoretical Implications. This study enriches the existing user experience theory through constructing the evaluation index system of user experience under cross-channel consumption by semistructured in-depth interview and grounded theory. Previous studies have either analyzed the impact of consumer behavior on channel decision-making based on mathematical models or focused on the antecedents of cross-channel behavior. However, the evaluation and analysis of cross-channel consumer experience from the perspective of consumers are lacked. This study builds a user experience evaluation index system to evaluate user experience under cross-channel consumption, in which the impact of different channels and channel switching on user experience can be measured. Then, BP network is used to verify the evaluation index system. We hope that the index system may pave the way for future empirical studies to improve user experience under cross-channel consumption and omni-channel retail so that businesses can gain competitive advantages.

Moreover, this study enriches the research on channel marketing and management theory. There are several types of cross-channels. Taking one of the type "search online and experience offline" of catering service industry as an example, we build the evaluation index system of user experience. In practice, the industries and types of cross-channel consumption are not limited to the above examples. It also includes industries such as retail and tourism as well as "experience offline, purchase online," "buy online and pickup in store" types. The evaluation index system constructed in this study can be extended to other industries and types of cross-channel consumption, with the relevant index parameters adjusted according to different scenarios. Therefore, it has a certain universality.

6.2.2. Managerial Implications. The evaluation index system constructed in this paper is helpful for managers to think about the enterprise's channel management systematically, make corresponding improvement in online and offline channel construction, and channel switching design and user analysis so as to improve enterprise competitiveness. 
Managers should pay special attention to the consistency of information and services under different channels and the coherence of different channels. Based on the analysis of consumers' needs and expectations, managers should strengthen the design of online and offline channel strategies, take effective measures to reduce the difficulty and cost of channel switching, and increase the fluency, convenience, and coherence of the connection between channels so that users can obtain seamless consumption experience.

In terms of online channel construction, managers should consider the design of online platform operation, online service, information, and promotion. In addition to strengthening the display of basic information of product, environment, price, and others, the information such as new categories, promotion activities should be timely updated. The management of online reviews should be strengthened. Consumers who provide high-quality, authentic, and illustrated comments can be rewarded with certain points, and their comments are recommended first. Comments that are not significant to consumers could be timely eliminated to reduce the time cost of consumer browsing. Comments that give medium and poor grades should be carefully analyzed and patiently replied. And improvement measures should be taken for the shortcomings in order to build a good reputation. In addition, online marketing strategies should be innovated constantly, such as adding live explanation and small video introduction for products and stores, package discounts so as to improve consumers' online experience.

In terms of physical store operation, businesses should take advantage of controllable factors of their internal and external resources and enhance users' perception of product quality, service quality, and environmental quality. On the basis of ensuring product quality and service level, businesses should innovate constantly such as paying attention to product iteration, increasing product types regularly, focusing on creating characteristic products or packages, improving the diversity and interchangeability of packages, and giving packages a certain degree of freedom so that consumers can have more choices. Value-added special services such as free goods and holiday discounts could be provided. Cooperation channels could be broadened by combining ecommerce platform, payment software, banks, and hotels so as to improve online and offline popularity.

Managers should pay attention to the improvement of environmental perception quality such as providing appropriate background music, changing store style according to the characteristics of seasons and segmentation of customers, and increasing environmental novelty so as to improve consumer stickiness. In order to obtain long-term competitive advantage, businesses should strengthen user research, grasp user needs, and make full use of events, trends, and changes in the external environment such as government policies, new technology of artificial intelligence, and internet of things that are conducive to their competitiveness and performance.

6.3. Limitations and Future Research. In this study, 36 users were selected for interviews, and the data coverage was rela- tively small. At the same time, the evaluation system constructed by taking grounded theory method has a certain subjectivity. In the future, user behavior data can be obtained through field experiments or big data analysis technology to build an evaluation index system.

This study uses neural network to verify the evaluation index system. In the future, other methods such as "factor analysis" can be used. In terms of evaluation methods, methods such as fuzzy comprehensive evaluation, and deep learning neural networks can also be used.

In addition, future research can compare different types of user experience under cross-channel consumption and explore the influencing factors and differences of user experience as well as the motivation of channel switching, so as to provide a better impetus for enterprises to carry out omnichannel sales and improve their business performance.

\section{Data Availability}

All data, models, and code generated or used during the study appear in the submitted article.

\section{Conflicts of Interest}

We declare that we do not have any commercial or associative interest that represents a conflict of interest in connection with the work submitted.

\section{Acknowledgments}

This paper is supported by the research project of Innovation and Entrepreneurship training program for College Students of Jilin University (no. 201910183457).

\section{References}

[1] J. Lewis, P. Whysall, and C. Foster, "Drivers and technologyrelated obstacles in moving to multichannel retailing," International Journal of Electronic Commerce, vol. 18, no. 4, pp. 43-68, 2014.

[2] A. Rangaswamy and G. H. van Bruggen, "Opportunities and challenges in multichannel marketing: an introduction to the special issue," Journal of Interactive Marketing, vol. 19, no. 2, pp. 5-11, 2005.

[3] T. Kollmann and M. Hasel, "Cross-channel cooperation: on the collaborative integration of online and offline business models of e-entrepreneurs and traditional SMES," International Journal of Entrepreneurship and Small Business, vol. 6, no. 2, pp. 212-229, 2008.

[4] S. Heitz-Spahn, "Cross-channel free-riding consumer behavior in a multichannel environment: an investigation of shopping motives, sociodemographics and product categories," Journal of Retailing and Consumer Services, vol. 20, no. 6, pp. 570-578, 2013.

[5] H. C. Chiu, Y. C. Hsieh, J. Roan, K. J. Tseng, and J. K. Hsieh, "The challenge for multichannel services: cross-channel freeriding behavior," Electronic Commerce Research and Applications, vol. 10, no. 2, pp. 268-277, 2011.

[6] P. C. Verhoef, S. A. Neslin, and B. Vroomen, "Multichannel customer management: understanding the research-shopper 
phenomenon," International Journal of Research in Marketing, vol. 24, no. 2, pp. 129-148, 2007.

[7] L. I. Fei, "Connation, cause and countermeasures of omni channel retailing_-_further discussion on how to meet China multi channel retailing revolution storm," Journal of Beijing Technology and Business University (Social Science), vol. 28, no. 2, pp. 1-11, 2013.

[8] P. C. Verhoef, P. K. Kannan, and J. J. Inman, "From multichannel retailing to omni-channel retailing: introduction to the special issue on multi-channel retailing," Journal of Retailing, vol. 91, no. 2, pp. 174-181, 2015.

[9] M. Banerjee, "Misalignment and its influence on integration quality in multichannel services," Journal of Service Research, vol. 17, no. 4, pp. 460-474, 2014.

[10] C. Ming-zhe and L. Ai-hua, "The research on the impact of multichannel integration on cross-channel retention behavior," China Business and Market, vol. 34, no. 6, pp. 41-50, 2020.

[11] P. Lan, "Omnichannel integration strategies for retailer information service and order fulfillment in the new retailing era: a systematic review and future research agenda," China Business and Market, vol. 34, no. 10, pp. 17-27, 2020.

[12] K. Picot-Coupey, E. Huré, and L. Piveteau, "Channel design to enrich customers' shopping experiences: synchronizing clicks with bricks in an omni-channel perspective-the direct optic case," International Journal of Retail and Distribution Management, vol. 44, no. 3, pp. 336-368, 2016.

[13] G. Fang-jie and Z. Wen-feng, "The digital transformation strategy for Chinese catering chain enterprise based on value chain theory," China Soft Science, vol. 11, pp. 134-142, 2020.

[14] Y. Yi, T. Yuwei, and C. Mingxiang, "Coupling and coordinating analysis of customer experience and brand attraction for catering industry based on big data: a case study of Changsha," The Theory and Practice of Finance and Economics, vol. 41, no. 6, pp. 141-148, 2020.

[15] R. Sousa and C. A. Voss, "Service quality in multichannel services employing virtual channels," Journal of Service Research, vol. 8, no. 4, pp. 356-371, 2006.

[16] R. A. Mittelstaedt, "Sasquatch. The abominable snowman, free riders and other elusive beings," Journal of Macro-marketing, vol. 6, no. 2, pp. 25-35, 1986.

[17] S. van Baal and C. Dach, "Free riding and customer retention across retailers' channels," Journal of Interactive Marketing, vol. 19, no. 2, pp. 75-85, 2005.

[18] S. Huang, C. Yang, and X. Zhang, "Pricing and production decisions in dual-channel supply chains with demand disruptions," Computers and Industrial Engineering, vol. 62, no. 1, pp. 70-83, 2012.

[19] B. Dan, C. Liu, G. Xu, and X. Zhang, "Pareto improvement strategy for service-based free-riding in a dual-channel supply chain," Asia-Pacific Journal of Operational Research, vol. 31, no. 6, pp. 1450050-1450340, 2014.

[20] P. Xu-Jin and G. Lei, "Pricing and promotion strategies in the dual-channel supply chain considering the free-riding behavior of consumers," Chinese Journal of Management Science, vol. 24, no. 10, pp. 86-94, 2016.

[21] Y. W. Zhou, J. Guo, and W. Zhou, "Pricing/service strategies for a dual-channel supply chain with free riding and servicecost sharing," International Journal of Production Economics, vol. 196, pp. 198-210, 2018.

[22] Y. Haoxiong, G. Ziyue, W. Hao, and Z. Chuan, "Optimal strategy of dual-channel supply chain considering cross-channel returns," Chinese Journal of Management Science, vol. 8, pp. 1-12, 2020.

[23] C. Wang, Y. Wang, J. Wang, J. Xiao, and J. Liu, "Factors influencing consumers' purchase decision-making in $\mathrm{O} 2 \mathrm{O}$ business model: evidence from consumers' overall evaluation," Journal of Retailing and Consumer Services, vol. 61, no. 4, p. 102565, 2021.

[24] D. Liang, Z. Dai, and M. Wang, "Assessing customer satisfaction of $\mathrm{O} 2 \mathrm{O}$ takeaway based on online reviews by integrating fuzzy comprehensive evaluation with AHP and probabilistic linguistic term sets," Applied Soft Computing, vol. 98, no. 4, p. 106847, 2021.

[25] T. Kollmann, A. Kuckertz, and I. Kayser, "Cannibalization or synergy? Consumers' channel selection in online-offline multichannel systems," Journal of Retailing and Consumer Services, vol. 19, no. 2, pp. 186-194, 2012.

[26] C. Jian and Z. Xiaodong, "The exploration of factors influencing consumption experience based on the $\mathrm{O} 2 \mathrm{O}$ model," Journal of Modern Information, vol. 34, no. 12, pp. 55-59+63, 2014.

[27] K. Dong, S. Kai, and Z. Ming-xiang, "How the O2O firms improve customer experience through the integration of online and offline-_-a conceptive model from partnership perspective," China Business and Market, vol. 31, no. 6, pp. 45-52, 2017.

[28] C. Chia-Chen, H. Kuo-Lun, and H. Cheng-Han, "Understanding usage transfer behavior of two way O2O services," Computers in Human Behavior, vol. 100, pp. 184-191, 2018.

[29] H. Yingying, Z. Ling, and F. Si, "Understanding the dual role of habit in cross-channel context: a dynamic perspective," Chinese Journal of Management, vol. 15, no. 4, pp. 598-607, 2018.

[30] Task Group, P. Shen, and D. Wan, "Influencing factors and driving mechanism of omni-channel retail experience value co-creation behavior," China Business and Market, vol. 33, no. 7, pp. 10-21, 2019.

[31] I. Maggioni, S. J. Sands, C. R. Ferraro et al., "Consumer crosschannel behaviour: is it always planned?," International Journal of Retail \& Distribution Management, vol. 48, no. 12, pp. 1357-1375, 2020.

[32] A. C. Haridasan, A. G. Fernando, and S. Balakrishnan, "Investigation of consumers' cross-channel switching intentions: a push-pull-mooring approach," Journal of Consumer Behavior, vol. 20, no. 5, pp. 1092-1112, 2021.

[33] Y. Yang, Y. Gong, L. P. W. Land, and T. Chesney, "Understanding the effects of physical experience and information integration on consumer use of online to offline commerce," International Journal of Information Management, vol. 51, no. 51, p. 102046, 2020.

[34] Y. Kim, Q. Wang, and T. Roh, "Do information and service quality affect perceived privacy protection, satisfaction, and loyalty? Evidence from a Chinese O2O-based mobile shopping application," Telematics and Informatics, vol. 56, p. 101483, 2021.

[35] S. Talwar, A. Dhir, V. Scuotto, and P. Kaur, "Barriers and paradoxical recommendation behaviour in online to offline (O2O) services. A convergent mixed-method study," Journal of Business Research, vol. 131, pp. 25-39, 2021.

[36] N. R. Pandit, "The creation of theory: a recent application of the grounded theory method," Qualitative Report, vol. 4, pp. 1-15, 2015. 
[37] Z. Zhongping, "Thoughts on the information literacy education of public library readers - based on the investigation and analysis of the current situation of readers' information literacy," Library Theory and Practice, vol. 3, pp. 40-42, 2014.

[38] K. Locke, "Qualitative research and evaluation methods," Organizational Research Methods, vol. 5, no. 3, p. 299, 2002.

[39] A. L. Strauss and J. M. Corbin, Basics of Qualitative Research: Techniques and Procedures for Developing Grounded Theory, Sage Publications, Thousand Oaks, 1998.

[40] Z. Cui, "Empirical study of offline experience characteristics on consumers' perceived value and re patronage intention," Enterprise Economy, vol. 2, pp. 84-91, 2020.

[41] G. Wei, L. Yi, and L. Xue, "Research on the relationships among omnichannel shopping experience, brand loyalty, and brand equity-C the moderating effect of consistent and seamless," Industrial Engineering and Management, vol. 24, no. 4, pp. 174-180+196, 2019.

[42] X. Zhang and D. Wang, "Study on influencing factors of individual medical and health information source selection behavior based on grounded theory," Library and Information Work, vol. 14, pp. 5-13, 2018. 